\title{
PROPERTIES OF Fe-Cr-Ni-Mn-Si (-Co) SHAPE MEMORY ALLOYS
}

Y. MORIYA, H. KIMURA, S. ISHIZAKI, S. HASHIZUME, S. SUZUKI, H. SUZUKI and T. SAMPEI

Steel Research Center, NKK Corporation, 1-1 Minamiwatarida, Kawasaki-ku, Kawasaki 210, Japan

\begin{abstract}
The shape memory performance and various properties of the Fe$\mathrm{Cr}-\mathrm{Ni}-\mathrm{Mn}-\mathrm{Si}(-\mathrm{Co})$ alloys were investigated. Those alloys were concluded to have the good shape memory performance, workability, machinability and corrosion resistance.
\end{abstract}

1. Introduction.

Shape memory effect which is characterized by the transformation of stressinduced $\varepsilon$ martensite has been reported in Fe-Cr-Nils, Fe-Mnzs and Fe-Mn-Si3s4s alloys. Especially, the Fe-Mn-Si alloy shows an excellent shape memory effect and much effort for their practical applications has been made on this alloy system5s. The authors have been also researching on ferrous shape memory alloys associated with the $\varepsilon$ martensite, and reported newly developed Fe-Cr-Ni-Mn-Si (-Co) shape memory alloys having a sufficient amount of the shape recovery and a good corrosion resistance6s-10). The purpose of the present paper is to describe the shape memory performance and the other various properties of the $\mathrm{Fe}-\mathrm{Cr}-\mathrm{Ni}-\mathrm{Mn}-\mathrm{Si}-$ (Co) shape memory alloys.

\section{Experimental procedure.}

The alloys used in the present study were prepared by vacuum induction melting. The chemical compositions of the alloys are shown in Table 1. After test plates hot-rolled were homogenized at $1323 \mathrm{~K}$ for $3.6 \mathrm{ks}$, test specimens were machined from the plates. The Ms points of these alloys which were measured using a thermal dilatometer were at around room temperature as shown in Table 1 . The magnitude of the shape recovery was measured using tensile specimens (diameter was $6 \mathrm{~mm}$ and gauge length was $30 \mathrm{~mm}$ ) by heating them up to $873 \mathrm{~K}$ after giving $4 \%$ of strain at room temperature. The shape recovery strain was defined as (the shape recovery length) / (the initial gauge length) $\times 100 \%$.

Otsuka et al.11) reported that the shape memory effect of Fe-Mn-Si alloys is remarkably increased by the repetition of $2.5 \%$ straining at room temperature and following annealing at $873 \mathrm{~K}$, and this cyclic process was called as "training". In the present study, the effect of the training cycles on the shape memory performance was also demonstrated. The applied strain and the annealing temperature of training cycles were set to be $4 \%$ and $873 \mathrm{~K}$ respectively which had been concluded to be optimum conditions from the results of preliminary experiments.

Table 1 Chemical compositions and Ms temperatures. (mass\%)

\begin{tabular}{|c|c|c|c|c|c|c|c|}
\hline $\mathrm{Cr}$ & $\mathrm{Ni}$ & Mn & $\mathrm{Si}$ & $\mathrm{Co}$ & Others & $\mathrm{Fe}$ & Ms \\
\hline 9.1 & 5.4 & 14.3 & 5.9 & 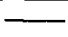 & $\mathrm{C}<100 \mathrm{ppm}$ & Bal. & $283 \mathrm{~K}$ \\
\hline 13.0 & 6.0 & 8.0 & 6.0 & 12.1 & $\mathrm{~N}<100 \mathrm{ppm}$ & & $285 \mathrm{~K}$ \\
\hline
\end{tabular}


3. Results and discussion.

\section{3-1. Shape memory performance.}

Figure 1 shows the effect of training cycles on the shape recovery strain of $\mathrm{Fe}-9 \% \mathrm{Cr}-5 \% \mathrm{Ni}-14 \% \mathrm{Mn}-6 \% \mathrm{Si}$ and $\mathrm{Fe}-13 \% \mathrm{Cr}-6 \% \mathrm{Ni}-8 \% \mathrm{Mn}-6 \% \mathrm{Si}-12 \% \mathrm{Co}$ alloys. The recovery strains were increased with the number of training cycles, and after three or larger numbers of training cycles, the recovery strains could reach more than $3 \%$. A similar result as shown in Fig, 1 was also reported in the earlier study ${ }^{1}$. Figure 2 shows the effect of training treatment on the relationship between the applied strain and the recovery strain. The line in the figure denotes perfect shape recovery. The amount of recovery strain depended on the applied strain, and the training treatment produced a remarkable effect to raise the recovery strain. After three times of the training treatment, the maximum recovery strain was obtained at around $6 \%$ of applied strain, and could reach more than $4 \%$ of which value was comparable to that of $\mathrm{Cu}$ based shape memory alloys.

Figure 3 shows the shape recovery behavior of $\mathrm{Fe}-9 \% \mathrm{Cr}-5 \% \mathrm{~N}-14 \% \mathrm{Mn}-6 \% \mathrm{Si}$ alloy which was measured by using a thermal dilatometer. The $20 \mathrm{~mm}$ long test piece was cut from the gauge portion of the tensile specimen which had been strained by $4 \%$ at room temperature beforehand. In the figure, the shape recovery behavior was clearly observed after a little thermal expansion at the early stage of heating. The starting temperature of the shape recovery was about $330 \mathrm{~K}$, and the finishing temperature was about $620 \mathrm{~K}$. The difference between those temperatures was fairly large in comparison with those of $\mathrm{Ti}-\mathrm{Ni}$ and $\mathrm{Cu}$ based shape memory alloys. Figure 4 shows the shape recovery demonstration of the sheet materials of the alloy by heating. The training-treated sheet sample (with the thickness of $0.2 \mathrm{~mm}$ and the width of $7 \mathrm{~mm}$ ) was bent at room temperature before heating. The maximum applied strain here was about $2 \%$ on the surface. Nearly perfect shape recovery was observed when the applied strain was less than $2.5 \%$

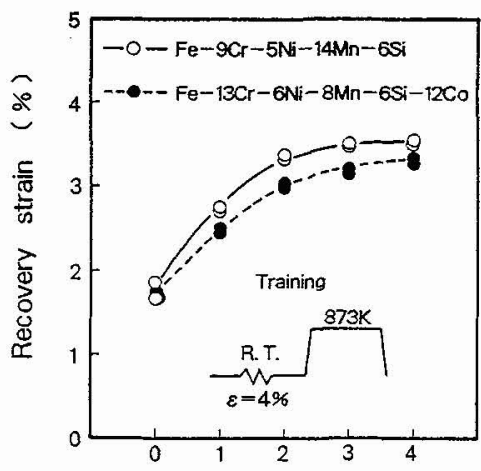

Number of training cycles

Fig. 1 Effect of training cycles on recovery strain.

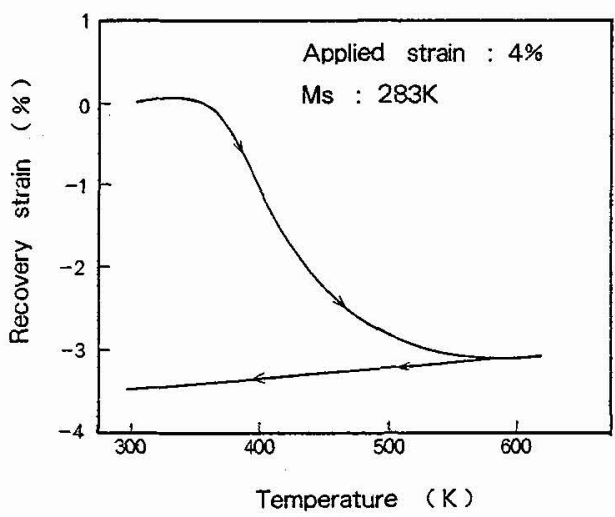

Fig. 3 Shape recovery behavior. $(\mathrm{Fe}-9 \mathrm{Cr}-5 \mathrm{Ni}-14 \mathrm{Mn}-6 \mathrm{Si})$

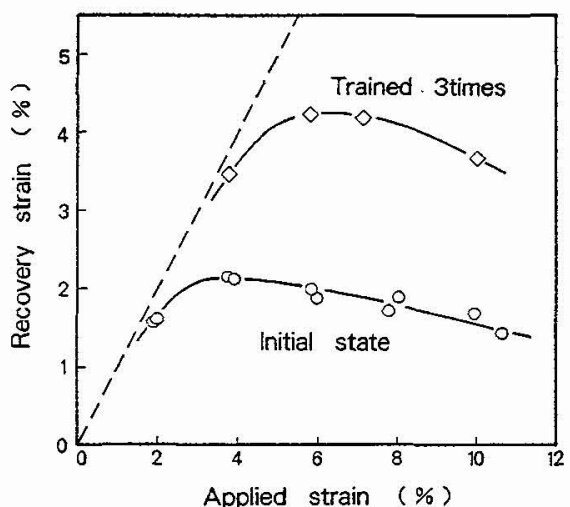

Fig. 2 Relationship between applied strain and recovery strain. ( $\mathrm{Fe}-9 \mathrm{Cr}-5 \mathrm{Ni}-14 \mathrm{Mn}-6 \mathrm{Si}$ )

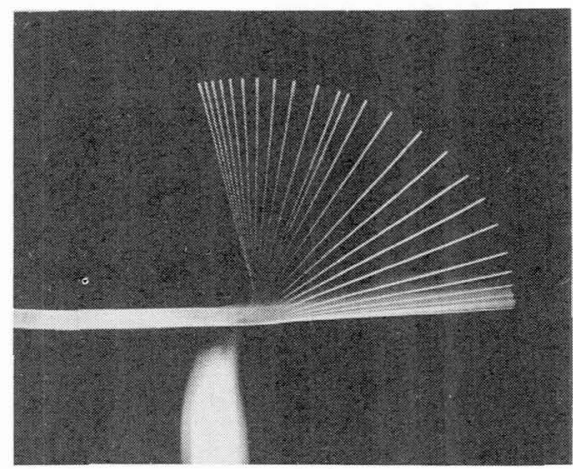

Fig. 4 Demonstration of shape recovery. 


\section{3-2. Mechanical properties.}

Figure 5 shows an example of measuring the shape recovery stress. The recovery stress was measured by the method as schematically illustrated in the figure. The specimen which had been strained by $4 \%$ at room temperature was heated from room temperature to $623 \mathrm{~K}$ at the rate of $0.3 \mathrm{~K} / \mathrm{s}$, and then cooled to room temperature. During heating, the specimen was constrained not to shrink more than $1 \%$. The recovery stress began to appear at the point where the recovery strain reached $1 \%$, and increased with the heating temperature. It is also noticed that during cooling, a stress peak was observed. The stress increase is due to thermal contraction and the stress drop due to the stress-induced martensitic transformation. The recovery stress finally obtained was about $170 \mathrm{~N} / \mathrm{mm} 2 \mathrm{at} \mathrm{room}$ temperature in this testing condition. The level of recovery stress was one third to fifth of that of $\mathrm{Ti}-\mathrm{Ni}$ alloy.

The tensile test results of the Fe-9\%Cr-5\%Ni-14\%Mn-6\%Si alloy at room temperature was shown in Table 2. It is recognized that the alloy had a enough strength and a good ductility as a structural steel.

Figure 6 shows the temperature dependence of the tensile and the proof strengths. The tensile strength dropped monotonously with the temperature increase, but the $0.2 \%$ proof stress showed a peculiar behavior. The proof stress showed the minimum value near the Ms point and the maximum value at around $390 K$. The drop of the proof stress observed with the temperature dependence from $390 \mathrm{~K}$ to the Ms point presumably resulted from the occurrence of stress-induced martensitic transformation.

Table 2 Results of tensile test at room temperature.

\begin{tabular}{|l|c|c|c|}
\hline $\begin{array}{l}0.2 \% \\
\text { proof stress }\end{array}$ & Tensile strength & Elongation & $\begin{array}{l}\text { Reduct ion } \\
\text { of ar ea }\end{array}$ \\
\hline $187 \mathrm{~N} / \mathrm{mm}^{2}$ & $816 \mathrm{~N} / \mathrm{mm}^{2}$ & $72 \%$ & $61 \%$ \\
\hline
\end{tabular}

Specimen diameter : $6 \mathrm{~mm}$, Gauge length : $30 \mathrm{~mm}$

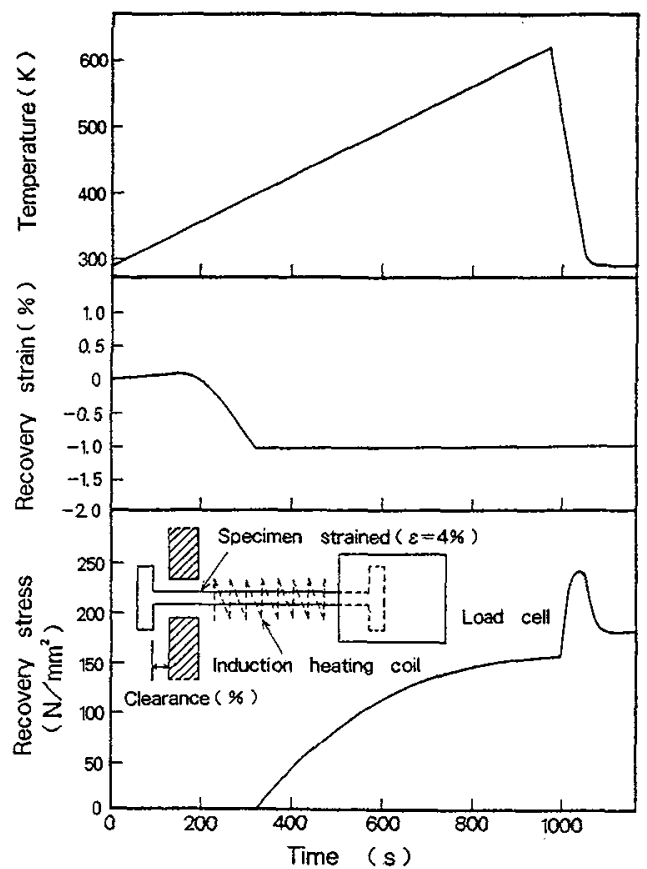

Fig. 5 Example of recovery stress. $(\mathrm{Fe}-9 \mathrm{Cr}-5 \mathrm{Ni}-14 \mathrm{Mn}-6 \mathrm{Si})$

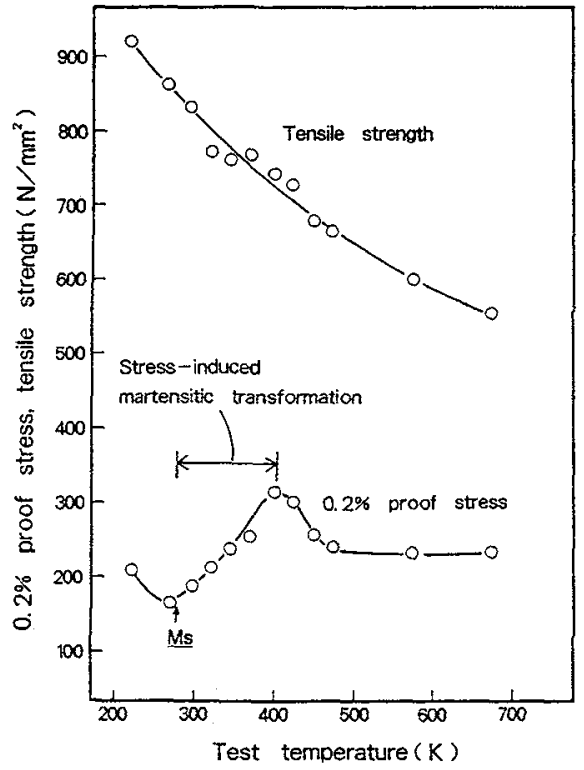

Fig. 6 Temperature dependance of tensile and proof strengths. $\left(F e-9 C_{r}-5 N i-14 M n-6 S i\right)$ 
3-3. Workability and machinability.

Figure 7 shows the temperature dependence of workability of the Fe-9\%Cr-5\%Ni$14 \% \mathrm{Mn}-6 \%$ Si alloy. Cracking of the alloy sheets with the initial thickness of $1 \mathrm{~mm}$ was visualiy checked at each pass of rolling operation. In the case of rolling operation at elevated temperatures, the alloy sheets were heated at each pass by a electric furnace to control the rolling temperature constant. The critical total reduction, the maximum value of reduction without causing any crack, was $30 \%$ at room temperature as shown in the figure. This value is fairly low compared with that of conventional steels, however it should be noted that the alloy still has a better cold workability than the non-ferrous shape memory alloys. Furthermore, the critical total reduction of the alloy could be increased by the rolling temperature as shown in the figure.

Figure 8 shows the effect of sulfur content on the tool life under drilling operations for the $\mathrm{Fe}-9 \% \mathrm{Cr}-5 \% \mathrm{Ni}-14 \% \mathrm{Mn}-6 \% \mathrm{Si}$ alloy. The tool life was defined as the total drilling depth under the experimental conditions as indicated in the figure, and the longer tool life, the alloy has the better machinability. The tool life of type 304 stainless steel was also shown in the figure as a comparison. In the region of the low sulfur content, the tool life of the alloy is the same level as that of the type 304 , thus the alloy has a good machinability for engineering use. It is possible to improve the machinability of the alloy by adding sulfur without impairing the shape memory effect.

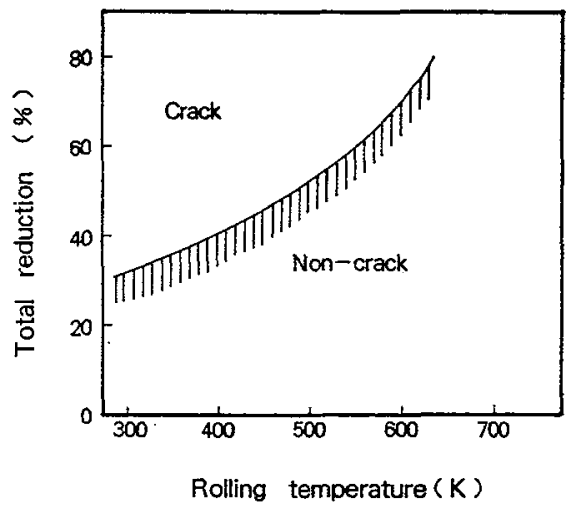

Fig. 7 Temperature dependance of workability in rolling operation. $(\mathrm{Fe}-9 \mathrm{Cr}-5 \mathrm{Ni}-14 \mathrm{Mn}-6 \mathrm{Si})$

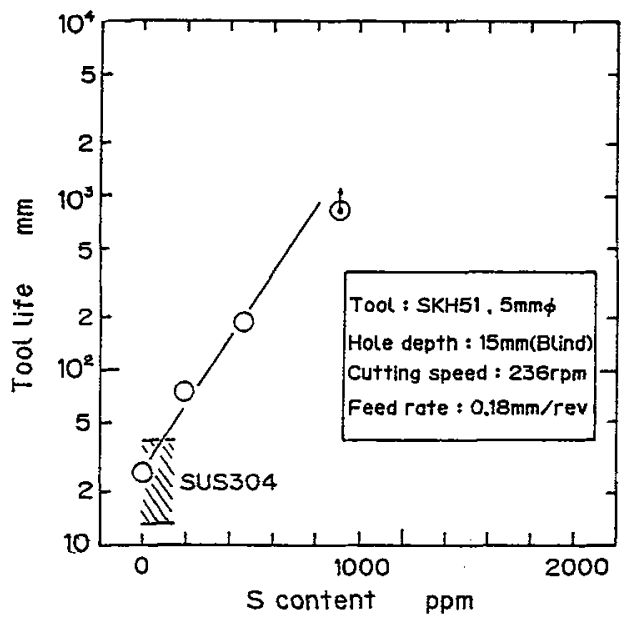

Fig. 8 Effect of sulfur content on tool life in drilling operation. (Fe-9Cr-5Ni-14Mn-6Si) 
3-4. corrosion resistance.

Figure 9 shows anodic polarization curves of the Fe-9\%Cr-5\%Ni-14\%Mn-6\%Si and $\mathrm{Fe}-13 \% \mathrm{Cr}-6 \% \mathrm{Ni}-8 \% \mathrm{Mn}-6 \% \mathrm{Si}$ alloys in $5 \% \mathrm{H}_{2} \mathrm{SO}_{4}$ aqueous solution at $303 \mathrm{~K}$ in comparison with that of type 304 stainless steel. The specimens were machined from the test plates after homogenization at $1323 \mathrm{~K}$. The passive current densities of the alloys, which is an index for the stable passive film formation, are as the same level as that of type 304 . This result suggests that the passive films of the alloys are as stable as that of type 304 under the condition tested. In view of earlier studies, the corrosion resistance of the alloys are fairly high when considering these $\mathrm{Cr}$ content levels. This advantageous corrosion resistance may be caused by $6 \%$ of $\mathrm{Si}$ addition though it is not confirmed yet.

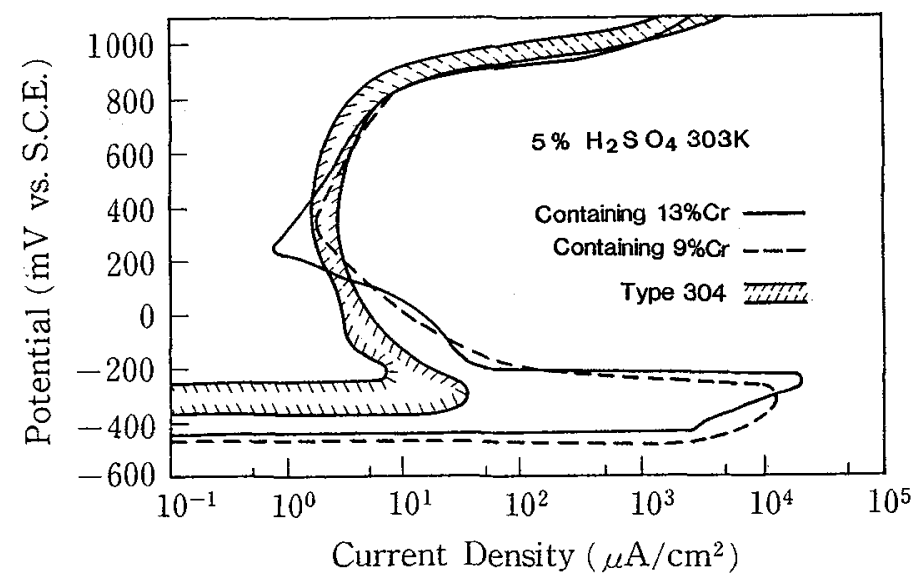

Fig. 9 Anodic polarization curves.

4. Conclusions.

The shape memory performance and the other various properties of the Fe-Cr$\mathrm{Ni}-\mathrm{Mn}-\mathrm{Si}(-\mathrm{Co})$ shape memory alloys were described in the present paper. It is concluded that the alloys have the good shape memory performance, workability, machinability and corrosion resistance.

\section{REFERENCES}

1) K. Enami, S. Nenno and Y. Minato: Scripta Met., 5, (1971), 663.

2) K. Enami, A. Nagasawa and S. Nenno : Scripta Met., 9, (1975), 941.

3) A. Sato, Y. Yamaji and T. Mori : Acta Met., 34, 2, (1986), 287.

4) M. Murakami, H. Otsuka, H. G. Suzuki and S. Matsuda : Proc. of Int. Conf. on Martensitic Transformations (ICOMAT-86), Nara, Japan, $(1986), 985$.

5) H. Ostuka, H. Yamada, H. Tanahashi and T. Murayama : Proc. of Int. Conf. on Martensitic Transformations (ICOMAT-89), Sydney, Australia, (1989).

6) Y. Moriya, S. Sampei, I. Kozasu and H. Tagawa : CAMP-ISIJ, 2, (1989), S299.

7) H. Kimura, I. Nakauchi, Y. Moriya, T. Okita and Y. Mihara: ibid., 2, (1989), S300.

8) S. Ishizaki, Y. Moriya, T. Shiraga and T. Sampei : ibid., 2, (1989), S301.

9) S. Hashizume, Y. Moriya and H. Suzuki: ibid., 2, (1989), S302.

10) Y. Moriya, H. Suzuki, S. Hashizume, T. Sampei and I. Kozasu : Proc. of Int. Conf. on Stainless Steels, Chiba, Japan, ISIJ, (1991), 527.

11) H. Otsuka, M. Murakami and S. Matsuda : Proc. of Materials Resarch Society (MRS) Int. Meeting on Advanced Materials, Tokyo, Japan, (1988). 